\title{
The influence of using heat storage with PCM on inlet and outlet temperatures in substation in DHS
}

\author{
Kinga Nogaj $^{1, *}$, Michat Turski ${ }^{1}$, and Robert Sekret $^{1}$ \\ ${ }^{1}$ Faculty of Infrastructure and Environment, Czestochowa University of Technology, \\ ul. Brzeznicka 60A, 42-200 Czestochowa, Poland
}

\begin{abstract}
The main objective of this article is to indicate the direction of development of new generation heating systems that use phase change materials, and the important criteria needed when choosing a phase change material. The work contains a detailed classification of materials using the latent heat of organic and inorganic PCM. This references the technical possibilities of existing heat storage technologies. A specific objective was adopted to determine the effect of using heat storage with PCM on inlet and outlet temperatures in substation in district heating systems. The scope of the study included determining the parameters of the heat distribution network as a function of an outdoor air temperature within the range of $20^{\circ} \mathrm{C}$ to $+12^{\circ} \mathrm{C}$. The object of analysis was chosen to be the heating system parameters: supply $120^{\circ} \mathrm{C}$ and return $60^{\circ} \mathrm{C}$. It is located on the surface of $160 \mathrm{~km}^{2}$, and supplies heat to 240,000 residents. The total length of the district heating network is $170 \mathrm{~km}$. Based on the study, it was found that the most advantageous material that accumulates heat depends on the return temperature in the heating network. For the above analyzed case, the return temperature was in the range of $46^{\circ} \mathrm{C}$ to $57^{\circ} \mathrm{C}$. The analysis showed that the most preferred materials using heat of phase change, have possible applications in heating networks and received a return temperature including salt hydrates, such as $\mathrm{MgSO}_{4} \cdot 7 \mathrm{H}_{2} \mathrm{O}$ and $\mathrm{Na}_{2} \mathrm{~S}_{2} \mathrm{O}_{3} \cdot 5 \mathrm{H}_{2} \mathrm{O}$. The introduction of stored heat for the district heating system with the phase change material in the form of salt hydrates, allows the return temperature in the district heating to remain at temperatures compatible with the adopted regulatory table for temperatures outside the standard heating season.
\end{abstract}

\section{Introduction}

The current development of district heating systems in light of changing regulations, presented in [1], seeks to increase the efficiency of existing systems, through the use of heat

\footnotetext{
${ }^{*}$ Corresponding author: k.nogaj@is.pcz.pl
} 
accumulators. Heat storage in this type of system can be realized through the use of sensible and latent heat, as shown in [2-4]. The use of sensible heat is usually a solution related to the heat storage source and is accomplished in buildings by means of accumulators stratification filled with water. Increasingly, more common technologies are using latent heat.

Storage technologies evolve continuously, and therefore the accumulation of heat through the material using the heat of phase change appears to be particularly interesting.

Phase change materials are organic and inorganic materials. Organic materials include paraffin, non-paraffin (e.g. fatty acids). Inorganic materials include salt hydrates, salt composites and alloys [5]. The classification of phase change materials is shown in Figure 1.

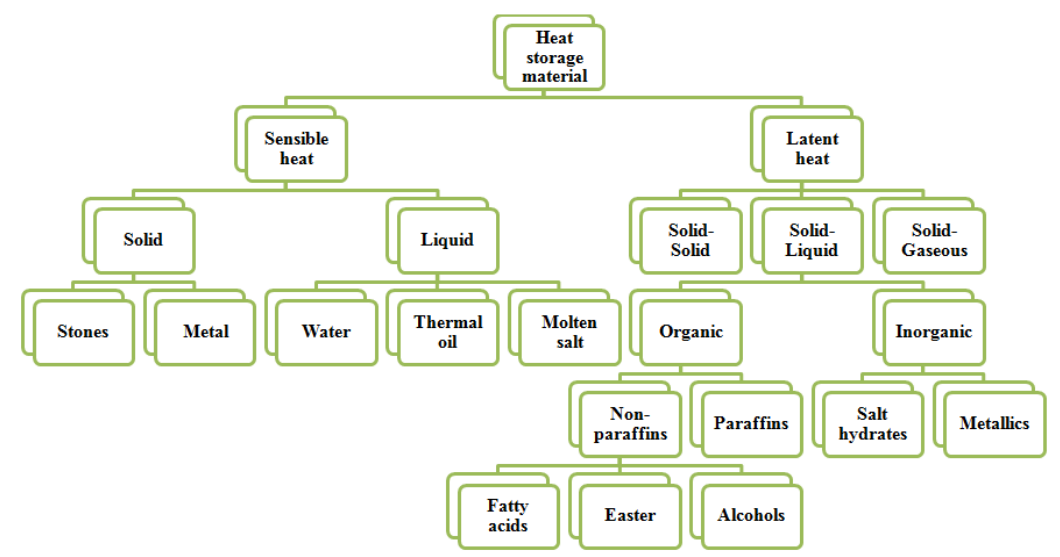

Fig. 1. Classification of phase change materials [2].

The selection of material utilizing the heat of phase change in the heat accumulator is the acceptance of the criteria for evaluating the individual aspects. Phase change materials must have high latent heat and high thermal conductivity. The melting point of materials using latent heat should be in the range of the operating conditions of work [6]. These materials should be subject to melting, minimum supercooling, should be chemically stable, non-toxic and should not cause corrosion. Depending on the application, the use of latent heat should be selected based on the content's melting point [7]. For the purpose of heat accumulation in heating systems, most matching characteristics determine the salt hydrates and paraffins [8].

\section{Methodology}

The heating system which was adopted for analysis is located in the third climate zone. The adjustment range of the heat distribution network is in the range of outside air temperatures from $-20^{\circ} \mathrm{C}$ to $+12^{\circ} \mathrm{C}$. The heating system parameters were chosen as the objects of analysis: supply $120^{\circ} \mathrm{C}$ and return $60^{\circ} \mathrm{C}$. The heating system is located on a surface of $160 \mathrm{~km}^{2}$, and supplies heat to 240,000 residents. The total length of the district heating network is $170 \mathrm{~km}$. An analysis of the substation was also conducted.

The analyzed substation, is an intermediate node (connected heating). It is single function node, in which hot water is prepared in electric heaters. The analysis was performed in three stages. The first phase was concerned with the designation of the operating parameters in relation to the outside temperature to the choice of material using heat of phase transitions. In the second stage, the possible set of heat to be stored in the 
heating system was determined. In the third step, the optimum volume of heat storage in order to maintain the return temperature at a constant level corresponding to the regulatory table was determined.

The first stage of analysis determined the return temperature in the district heating network, which allowed for determining the amount of the heat that is not picked up by the end users with respect to the design conditions. The parameters of the heat distribution network has been established in accordance with the regulatory table for temperatures outside in the standard heating season. Then, the obtained data were compared with design values. On the basis of these results the phase change material was chosen for the analysed case.

In the second stage, the calculated computational amount of heat consumption by end users allowed the determination of the amount of heat that was possible to store in a district heating network. Return temperatures in the heating network were the values of the deliverables of heat supplied to end users. The dynamic state of the heating system also made it possible to calculate the heat flux in order to cover the thermal needs of end users, depending on the temperature of the outside air. The heat flux in this analysis, was equal to $1,206.30 \mathrm{~kg} / \mathrm{s}$.

In the third step the choice of the optimum volume of the heat storage was made with the estimated amount of heat able to be stored in a substation, which depended on the specific heat of the PCM material in both solid and liquid form, and the enthalpy changes during the phase change.

\section{Results and analysis}

By joining the selection of phase change material used in heat stores the return temperature of the district heating network should first be determined. Figure 2 shows the return temperature design conditions (blue) for a standard heating season (red). Conditions of the design return temperature in heating networks are based on the outside temperature assuming $100 \%$ heat consumption by users. Standard heating season refers to the actual values, which are dependent on consumption of heat related to heat demand in relation to outside temperatures.

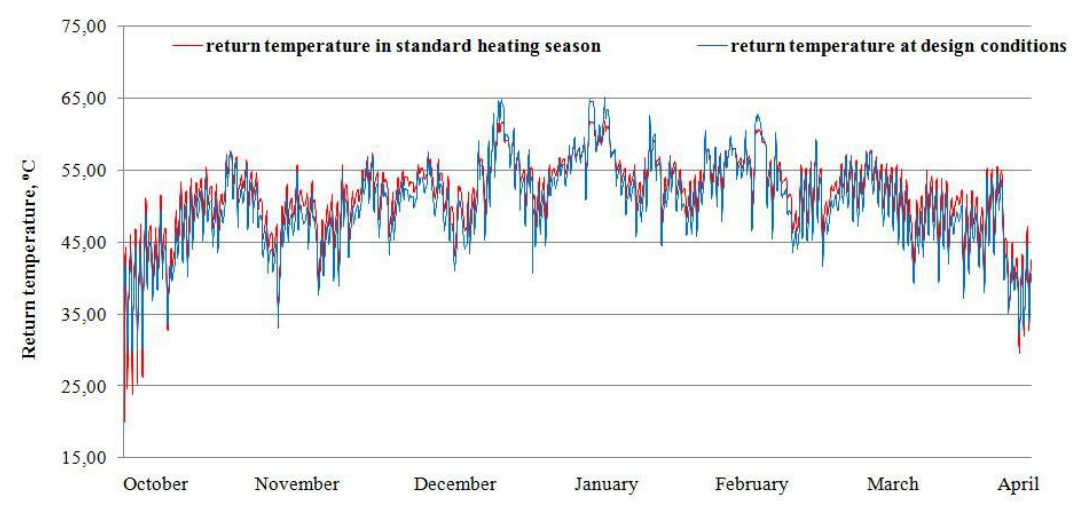

Fig. 2. Summary of return temperature in the district heating network for a standard heating season and the design of the return temperature.

Comparing the values of the two states in the district heating network, it can be seen that the return temperature in both cases (standard heating season - blue, and the design 
value of the return temperature of the district heating network - red) is in the range of $46^{\circ} \mathrm{C}$ to $57^{\circ} \mathrm{C}$, as shown in figure 3 . These temperatures occurred with the greatest frequency in the months between December and March. Other months of the heating season are, characterized by slightly lower return temperatures (below $46^{\circ} \mathrm{C}$ ). The return temperatures for the standard heating season are 3\% higher than the design conditions for the system.

Whatever the reason for this estimated discrepancy, it is possible to reduce disparities through the use of distributed heat storage located at the ends of the heating network.

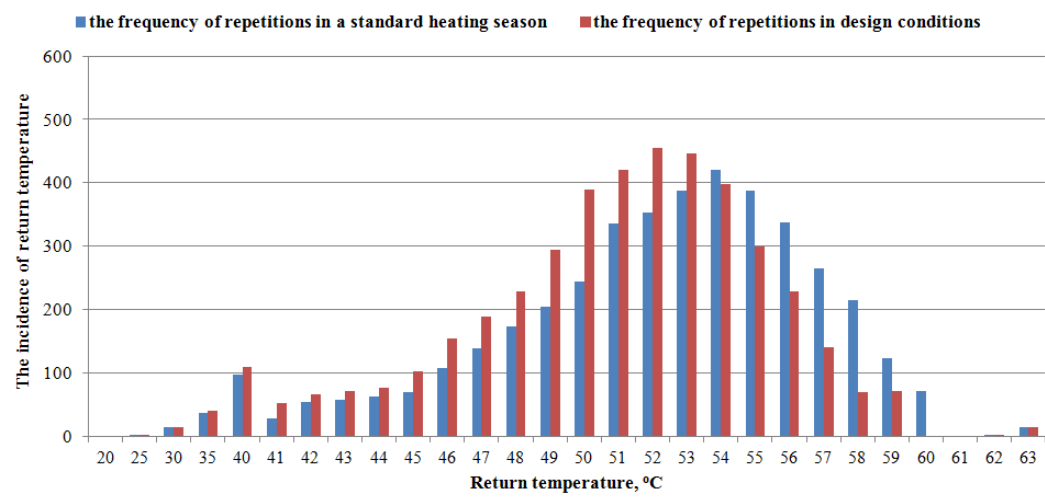

Fig. 3. Figure ordering the incidence of return temperatures in the district heating network.

\section{a. Choosing a phase change material for a representative heating system}

Based on the analysis of the frequency of return temperatures in the district heating system, the temperature of phase change was determined and, the material using the heat of phase change requires heat accumulation in the heating system. The analysis shows that the most common return temperature of the district heating network is in the range is of $46^{\circ} \mathrm{C}$ to $57^{\circ} \mathrm{C}$ and for that range of temperatures, a material utilizing heat of phase change will be selected.

Table 1 shows the salt hydrates and paraffins that have a carbon number from 23 to 26 . All selected materials undergo a phase change within the temperature range of the system's operation and have certain physical parameters chemical and technical. Highlighted are those compounds which, in accordance with the methodology proposed in the paper [8] obtained the highest number of points.

Table 1. The melting point and latent heat of phase change: salt hydrates and paraffin.

\begin{tabular}{|c|c|c|c|c|c|}
\hline Material & Melting point $\left({ }^{\circ} \mathrm{C}\right)$ & $\begin{array}{l}\text { Latent heat of } \\
\text { fusion }(\mathrm{kJ} / \mathrm{kg})\end{array}$ & $\begin{array}{c}\text { Thermal } \\
\text { conductivity } \\
\left(\mathbf{W} / \mathbf{m}^{*} \mathbf{K}\right)\end{array}$ & Density $\left(\mathrm{kg} / \mathrm{m}^{3}\right)$ & \begin{tabular}{|c} 
The resulting points \\
of selected materials \\
(according to the \\
method [8])
\end{tabular} \\
\hline $\mathrm{Mg}\left(\mathrm{NO}_{3}\right)-4 \mathrm{H}_{2} \mathrm{O}$ & 47 & 142 & 0,125 & 552 & 385,5 \\
\hline $\mathrm{Ca}\left(\mathrm{NO}_{3}\right) \cdot 4 \mathrm{H}_{2} \mathrm{O}$ & 47 & 153 & 0,191 & 540 & 385,5 \\
\hline $\mathrm{Fe}\left(\mathrm{NO}_{3}\right)_{3} \cdot 9 \mathrm{H}_{2} \mathrm{O}$ & 47 & 155 & not available & not available & 367,5 \\
\hline $\mathrm{Na}_{2} \mathrm{SiO}_{3} \cdot 4 \mathrm{H}_{2} \mathrm{O}$ & 48 & 168 & 0,265 & not available & 376,5 \\
\hline $\mathrm{K}_{2} \mathrm{HPO}_{4} \cdot 3 \mathrm{H}_{2} \mathrm{O}$ & 48 & 99 & not available & not available & 367,5 \\
\hline $\mathrm{Na}_{2} \mathrm{~S}_{2} \mathrm{O}_{3} \cdot 5 \mathrm{H}_{2} \mathrm{O}$ & 48,5 & 210 & not available & not available & 367,5 \\
\hline $\mathrm{MgSO}_{4} \cdot 7 \mathrm{H}_{2} \mathrm{O}$ & 48,5 & 202 & 0,163 & 490 & 385,5 \\
\hline $\mathrm{Ca}\left(\mathrm{NO}_{3}\right)_{2} \cdot 3 \mathrm{H}_{2} \mathrm{O}$ & 51 & 104 & not available & not available & 367,5 \\
\hline $\mathrm{Zn}\left(\mathrm{NO}_{3}\right)_{2} \cdot \mathrm{H}_{2} \mathrm{O}$ & 55 & 68 & not available & not available & 367,5 \\
\hline $\mathrm{FeCi}_{3} \cdot 2 \mathrm{H}_{2} \mathrm{O}$ & 56 & 90 & not available & not available & 367,5 \\
\hline $\mathrm{Ni}\left(\mathrm{NO}_{3}\right)_{2} \cdot 6 \mathrm{H}_{2} \mathrm{O}$ & 57 & 169 & not available & not available & 367,5 \\
\hline Paraffin of carbon number of 23 & 47,5 & 232 & 0,21 & 910 & 382,5 \\
\hline Paraffin of carbon number of 24 & 50,6 & 255 & 0,21 & 910 & 382,5 \\
\hline Paraffin of carbon number of 25 & 49,4 & 238 & 0,21 & 910 & 382,5 \\
\hline Paraffin of carbon number of 26 & 56,3 & 256 & 0,21 & 910 & 382,5 \\
\hline
\end{tabular}




\section{b. The amount of heat for the storage of the analyzed system}

In the standard heating season, the greatest possible amount of heat to be stored (above $20000 \mathrm{GJ} / \mathrm{a}$ ) was observed in December, January and February, as shown in Figure 4. In the remaining months, the amount of heat able to be stored had various amounts ranging between $3700 \mathrm{GJ} / \mathrm{a}$ and $19000 \mathrm{GJ} / \mathrm{a}$. Given the lack of data on full months in October and April (the analysis concerned the heating season, ie. the period from October 10 to April 8) it can be concluded that the highest possible amount of heat to be stored falls during the heating season (December 22.5 thous. GJ/a, January 25.9 thous. GJ/a, February 21.7 thousand. GJ/a), and the lowest during the transitional period (March and November of approximately 19 thous. GJ/a, October 8,8 thous. GJ/a April and a 3.7 thous. GJ/a).

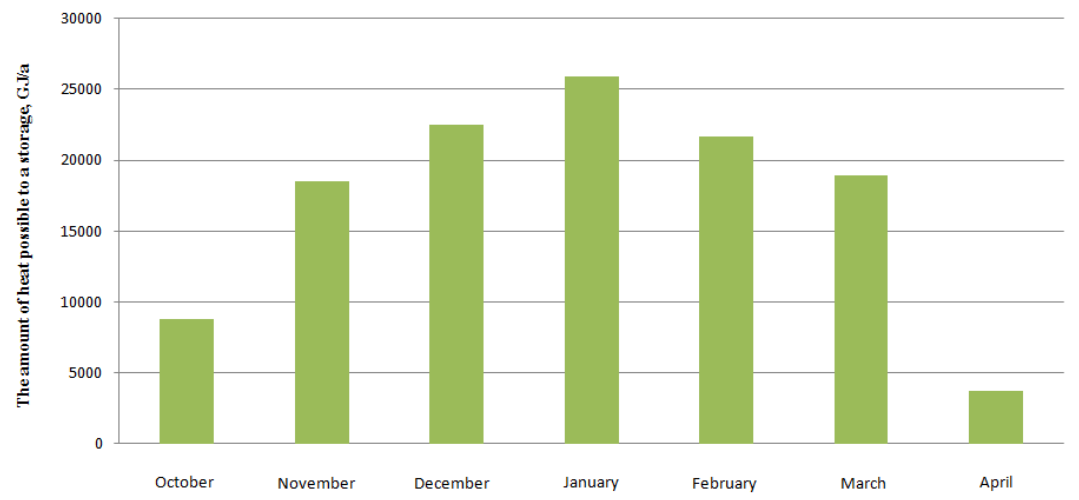

Fig. 4. The amount of heat available for storage in a standard heating season.

\section{c. Selecting the optimum volume of the heat storage accumulator using the phase change material}

For the analyzed substation it is estimated that the greatest possible amount of heat to be stored is available when the outside air temperature reaches a value in the range of $-2^{\circ} \mathrm{C}$ to $+5^{\circ} \mathrm{C}$. There it was observed, that the scope of the return temperature in the system reaches in the range of $46-57^{\circ} \mathrm{C}$.

The selection of the optimum volume of the heat storage by using phase change material is shown in Figure 5. The blue color indicates the temperature of the water supply system and the brown color the return water temperature. Also plotted are characteristic amounts of heat available to be stored in the analyzed system, which is shown by a green curve. The course of heat storage with phase change material within the temperature range of the installation in relation to ambient air temperature is marked in red.

When thermal energy storage systems using heat of phase change have the biggest influence on the amount of heat absorbed during the process of charging and discharging there is a temperature change in the system. Until the desired temperature in the system is reached, stored heat uses the heat capacity of water. In a specific temperature range (analyzed case $46^{\circ} \mathrm{C}-57^{\circ} \mathrm{C}$, where $\Delta \mathrm{T}=7 \mathrm{~K}$ ), the phase change and the proper storage of heat are both taking place. After exceeding the range of the optimum conditions for phase change, heat is again stored using the specific heat of water which is contained in the heat accumulator. 


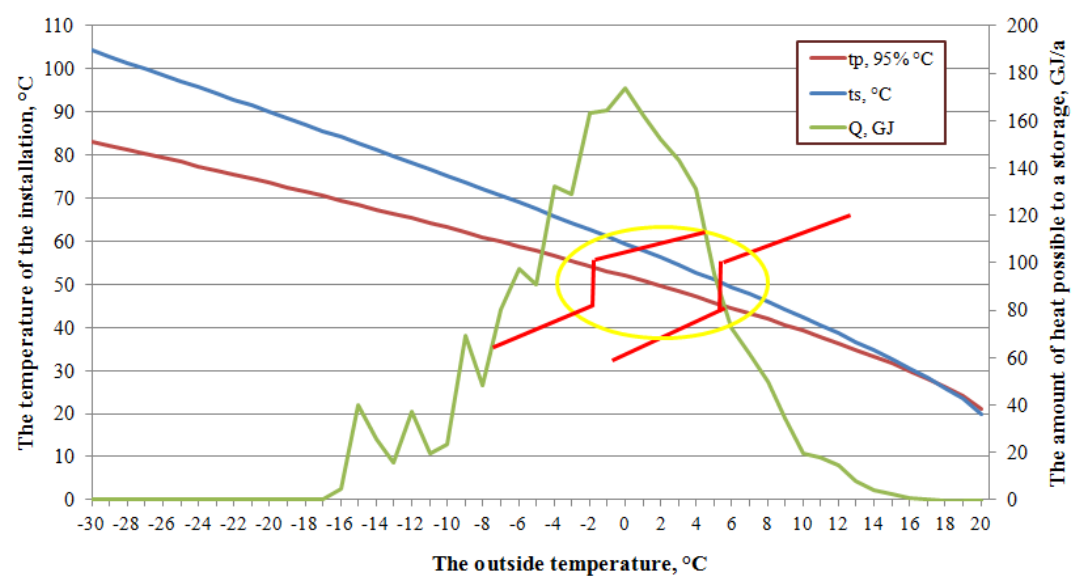

Fig. 5. Selection of the optimum volume of the heat accumulator in the analyzed heat substation.

The advantage of the latent heat above over the sensible heat is that it is easily assessable when comparing the even volume and mass required to store a certain amount of heat. With respect to the unit of weight and volume use of the phase change material stores heat in the heating network can increase the amount of heat possible to be stored by $30 \%$, in relation to aqueous heat storage.

\section{Summary}

The analysis states, that choosing the most favorable material accumulating heat depends on the return temperature heating network. Therefore, in any case, the choice of material using heat of phase change should be performed individually.

In this analysis, the most preferred materials for the heat storage utilizing latent heat in the heating network are salt hydrates, i.e. $\mathrm{Na}_{2} \mathrm{~S}_{2} \mathrm{O}_{3} \cdot 5 \mathrm{H}_{2} \mathrm{O}$ and $\mathrm{MgSO}_{4} \cdot 7 \mathrm{H}_{2} \mathrm{O}$ and paraffins having a carbon number of 24 and 26.

The analysis also showed that for the analyzed heating system present in significant quantities produced but not received amount of heat (approx. 120 thousand. GJ per heating season), which can be accumulated and used in periods of increased demand for heat. This amount represents approximately $5 \%$ of the total heat production.

Heat storage using phase change materials provides a much higher density of storage at a lower temperature difference between the loading and discharge of the heat accumulator.

The use of heat storage with heat of phase change, keeps the return temperature in the system at a required level in accordance with the regulatory table.

\section{References}

1. M. Turski, R. Sekret, Ryn. En. 4, 27-34 (2015)

2. A. Abhat, Sol. En. 30, 4, 313-332 (1983)

3. P. Feliński, M. Turski, R. Sekret. COW 10, 416-421 (2013)

4. J. Xu., R.Z. Wang, Y. Li. Sol. En. 103, 610-6380 (2014)

5. G. Ziskind, Adva. in Ther. En. Stor. Sys. 307-324 (2015) 
6. J.K. Basakayi, V.V.C.P. Storm, Internat. Jour. of Adva. in Engin. \& Tech. 7, 3, 692-700 (2014)

7. L.F. Cabeza, I. Martorell, L. Miro, A.I. Fernandez, C. Barreneche, Advan. in Ther. En. Stor. Sys. 1-26 (2015)

8. K. Nogaj, M. Turski, R. Sekret, COW 48, 3, 91-95 (2017) 